\title{
Medical ethics: an excuse for inefficiency?
}

\author{
Gavin Mooney Health Economics Research Unit, Department of Community Medicine, Aberdeen University
}

\section{Author's abstract}

There is frequently an appearance of conflict between medicine and economics. This arises first because the nature of health and health care requires the doctor to make decisions on behalf of the patient and thus serves to explain why medical ethics exist. But secondly it is due to the relative lack of acceptance of the ethics of the common good within medical ethics. As a result while economics in the field of health has as an objective the maximisation of the health of the community, subject to resource constraints, medical ethics pushes individual doctors to try to maximise the health of their patients. There is no reason to believe that the latter will sum to the former. To make the maximisation of health of the community the goal of the medical profession requires institutional changes, particularly with regard to budgeting, which will cajole and if necessary coerce doctors to adopt the good of the community as their objective.

\section{Why medical ethics?}

From an economic perspective, health care is a productive process which consumes scarce resources which have alternative, desirable uses. The output obtained is improved health status - which has various interesting characteristics such as being difficult to define, measure and value. The objective of any healthcare system should include some attempt to be efficient ie to maximise the health of the community with the resources available. (For more discussion of these issues see Culyer (1) and Mooney (2).) In many respects production of health care is similar to that of other goods. Yet, in medicine (and it is necessary to distinguish here between medicine and health care), ethical codes are more important than in any other productive process. What is different about medicine? The answer is that for 'normal' goods and services books, concerts, lawn-mowers - the individual is faced with a range of products about which he has various pieces of information concerning the satisfaction he is likely to derive from them. Of course, it is not always

\section{Key words}

Health care; health care economics; resource allocation; medical ethics. the case that the expected satisfaction (the basis of a consumer decisions) will equate with realised satisfaction. As Arrow (3) has suggested, howeveis 'Medicine, along with the other professions, distinctive in that the specialisation is in shee्f information'. Thus the patient is very much in the hands of the doctor because the asymmetry in information between the two parties results in a seriou impairment of the individual's autonomy as a decisionof maker. Arrow continues that in medical care 'the usu制 reasons why the market acts as a check to ensure quality operate . . . with very weak force. It is for this reason that ethical indoctrination of physicians is $\Phi^{9}$ such crucial importance. The control that is exercised ordinarily by informed buyers is replaced ôे internalised values' (3).

Individual patients are often ill-informed and it the role of the doctor to attempt to estimate what the individual would do if 'perfectly prudent'. But in orde? for the patient to accept this role he or she needs to $\overrightarrow{b \vec{B}}$ reassured that the doctor will act in a way that can be equated with how the patient would act were the patient perfectly prudent. Here, in other words, is another way of seeing medical ethics. The patient needs a medical-ethical code to serve to reassure hir that the doctor is acting in his (the patient's) bes? interests.

\section{Some problems}

Medical ethics was born at a time when the individuâ ethics of virtue and duty dominated the relationship between doctor, as supplier of health care and patient; as consumer. While the market for health care ho changed radically, medical ethics has stayed still.

Jonsen and Hellegers (4) suggest that as a resuR there is a neglect of 'the ethical issues arising from the intersection of multiple actions in institutions and society' and that, in respect of medical ethics, 'S⿴囗十 adequate (my emphasis) definition calls for an explic reflection on the morality of institutions and the relationship, and possible clash, between social values and individual values'. In short, medical ethics lacks concept of the common good.

The simple points I want to emphasise are:

(i) there is a gap in medical ethics - it is a two-legged 
stool (virtue and duty);

(ii) the medical profession do not recognise the existence of this gap or, perhaps more cynically, recognise its existence but, for whatever reasons, choose to attempt to ignore it;

(iii) two-legged stools are unstable;

(iv) a third leg is available, and is sometimes, if rather precariously, in place - despite the medical profession put there by (frequently) health service administrators; (v) unless the third leg (that of the common good) is recognised by the medical profession, the other two legs may come increasingly under strain to the detriment of many, not least the medical profession.

By making these points I do not want to suggest that the medical profession, either as individuals or corporately, should be responsible for determining what social ethics, the third leg, should constitute. Instead they should recognise to a much greater extent than is currently the case the role of others in determining social ethics and indeed social goals and priorities. There is too often a simplistic assumption on the part of doctors that, for example, clinical freedom is to be defended literally at all costs - even when these costs result in inefficiency in the sense of failing to maximise the health of the community.

\section{The conflict}

By now the essence of the apparent conflict between medical ethics and economics should be becoming clear: it is that while medical ethics is currently conceived in terms of the individualistic ethics of duty and virtue, economics embraces a concept of social ethics as well as individual ethics. This does not lead to the conclusion that economic values should replace medical ones nor that economics should operate to the exclusion of medical ethics in health care. (In this respect my views have been misrepresented by Kennedy (5)). It has to be stressed that economics and therefore economists certainly have to operate with values (their attempts at value-free analysis are doomed to failure) but they need not be, indeed I would argue should not be, consciously or otherwise the values of economists qua economists. No, the idea of economics is rather different. As Arrow (3) states: 'No economic or decision analysis can define values as such, but by providing a suitable language they can go some distance toward removing inconsistencies and assisting decision makers in achieving clarification of their own underlying value structure'.

Each doctor following individualistic ethical objectives will be concerned to maximise the benefit he can bestow on his patients. To this end he will attempt to obtain more and more scarce resources to assist him in this goal. Such an attempt - which ignores the opportunity-cost to other doctors' patients - is legitimised by the ethics of virtue and of duty. Ignoring, or attempting to ignore, the common good means that it can only be by accident that this atomistic set of actions by each individual doctor pursuing the maximising of health of their patients can lead to the maximum health with available resources for the population at large. It is not just that $\mathrm{Dr}$ Paul ignores his robbing of Dr Peter's patients: medical ethics in a sense implores him to assume every other doctor's patients out of existence (and also, possibly, the potential patients of his own of whom he is as yet unaware).

Again I would emphasise that I am not suggesting that doctors should be responsible for defining the common good. Rather they need to accept more readily that the common good as defined by administrators, authority members and politicians is a legitimate item and in the end often of overriding concern on the agenda of health care evaluation and planning.

Consequently the appearance of conflict occurs because of the discomfort which economic analysis in health care may create for the medical profession. This may arise for one of two reasons. First, doctors may be unhappy to have pointed out to them in an explicit way what their values are - or at least what values are consistent with the way in which they behave, particularly, but not solely, in the context of ethics. Secondly it may be that doctors recognise that economics may lead to a challenging of their existing values with which they currently feel comfortable and which they do not wish to give up. To have highlighted the fact that individual doctors' values in aggregation are not conducive to the goal of maximising the health of the community at large from the resources available may prove rather disturbing for doctors.

In the more specific context of the National Health Service (NHS) the emphasis which economists place on the issue of asymmetry of information may have disturbing repercussions for doctors. As Majone (6) has written in a related context 'the phenomenon of differential access to information transforms the problems of improving our understanding from the purely scientific and technical realm of information generation, dissemination and utilization, to the "political" arena'. As a result of the fact that "very concrete regulatory decisions' (such as those surrounding the NHS as an institution) 'may depend on basic philosophical attitudes, it is not surprising that policy actors allocate resources toward altering societal values and beliefs'. Given the special position of doctors as 'policy actors' in the NHS, it may well be that to the extent that they do exercise the power to alter social values and beliefs about both the NHS and medicine, they do so for self-interested reasons. Were they to be 'found out' then clearly very real problems might exist for the medical profession, for the NHS as a social institution or for both.

\section{The way forward}

In making these points it is not the intention to be in any way pejorative about members of the medical profession. I merely wish to point out that it is inevitable that they will to some extent operate out of 
self-interest and perhaps to such an extent as to be damaging to the NHS as an institution.

Fortunately - for the medical profession, patients, society at large and indeed for the NHS - there is a solution to this problem which consists largely of a widening of the definition of medical ethics. It is a solution which does not impinge on clinical freedom any more than existing arrangements and which in no way detracts from the importance of virtue and duty in medical ethics. All that is required is that the medical profession as a corporate body actively take part in the development of the third leg of the ethical stool - the common good.

Some readers, indeed some doctors, may be already persuaded of the need for the embracing of the ethic of the common good by medical ethics. However, that is not enough. Certain institutional alterations in the NHS, for example new budgeting structures and the acceptance of efficiency as a social goal, are required in order to promote the type of behavioural change which will make doctors act in the interests of the common good to a greater extent than is now the case. These institutional changes - essentially to provide incentives in the system to allow a more fruitful pursuit of efficiency ie maximising health benefits to the community from the resources available - are best achieved (perhaps can only be achieved) with the wholehearted support of the medical profession.

\section{Acknowledgements}

I should like to acknowledge comments from members $\vec{S}$. of the Health Economics Research Unit (HERU) and? from Robin Downie, Steve Engleman and Elizabetle Russell on earlier drafts of this paper. I am also gratefuf? to Muir Gray for helping to stimulate my interest in medical ethics. Finally, I wish to acknowledg로. financial support from the Scottish Home and Health Department. Any errors and the value judgement $\mathscr{乛}$ expressed remain of course my sole responsibility.

\section{References}

(1) Culyer A J. Need and the National Health Service London: Martin Robertson, 1976.

(2) Mooney G H. Values in health care. In: Lee K, ed Economics and health planning. London: Croom Helm 1979.

(3) Arrow K J. Government decision making and the preciousness of life. In Tancredi L R, ed. Ethics of healt care. Washington DC: National Academy of Sciences@ 1974.

(4) Jonsen A R, Hellegers A E. Conceptual foundations fo $\overrightarrow{\vec{G}}$ an ethics of medical care. See reference (3).

(5) Kennedy I. The unmasking of medicine. London: Paladin 1983: 185.

(6) Majone G. Institutional choice and social regulation: the casథ of environmental and occupational health standards. Laxenburg, Austria: International Institute for Appliego Systems and Analysis, 1981. 